Research Article

\title{
Unloading Mechanics and Energy Characteristics of Sandstone under Different Intermediate Principal Stress Conditions
}

\author{
Yingjie Zhang $\mathbb{D}$, Jiangteng Li $\mathbb{D}$, Gang Ma, and Shuangfei Liu \\ School of Resources and Safety Engineering, Central South University, Changsha 410083, China \\ Correspondence should be addressed to Jiangteng Li; ljtcsu@csu.edu.cn
}

Received 23 February 2021; Revised 26 March 2021; Accepted 12 April 2021; Published 22 April 2021

Academic Editor: Yunteng Wang

Copyright (c) 2021 Yingjie Zhang et al. This is an open access article distributed under the Creative Commons Attribution License, which permits unrestricted use, distribution, and reproduction in any medium, provided the original work is properly cited.

\begin{abstract}
The TRW-3000 true triaxial rock testing machine was used to conduct loading and unloading tests of sandstone under different $\sigma_{2}$, and the true triaxial lateral unloading mechanics and energy characteristics of sandstone under different $\sigma_{2}$ were studied. The experimental results show the following: (1) compared with the results of the loading test, the peak strength of the sandstone under the unloading $\sigma_{3}$ path is reduced, the unloading direction has obvious expansion and deformation, and the amount of expansion increases significantly with the increase of $\sigma_{2}$; sudden brittle failure occurs at the end of unloading. $E$ gradually decreases with the increase of $H$, and it performs well to use the cubic polynomial to fit the curve of $E$ - $H$. (2) The Mogi-Coulomb strength criterion can accurately describe the true triaxial strength characteristics of sandstone under loading and unloading conditions. Compared with the results of the loading test, the values of $c$ and $\varphi$ obtained based on this criterion under the unloading $\sigma_{3}$ path are reduced. (3) Under the condition of unloading $\sigma_{3}, U, U^{e}$, and $U^{d}$, when the specimen is broken, are all linearly positively correlated with $\sigma_{2}$. $U^{d}$ increases nonlinearly with the increase of $H$, and as $\sigma_{2}$ increases, the slope of the $U^{d}-H$ curve becomes larger, and the specimen consumes more energy under the same unloading amount. Most of the energy absorbed by the specimen under the unloading $\sigma_{3}$ path is converted into $U^{e}$, but as $\sigma_{2}$ increases, $U^{d} / \mathrm{U}$ increases, and the energy consumed when the specimen is broken is greater.
\end{abstract}

\section{Introduction}

The stress redistribution induced by the excavation of underground engineering and slope engineering results in obvious unloading deformation of the excavation face [1], which will cause serious engineering problems such as landslides, mine roof fall, slabs, and goaf collapses. If the surrounding rock is in a high-stress environment, the sudden release of the internally accumulated energy in the excavation process may also cause a large-scale rock burst [2]. The mechanical behaviors of rocks under unloading are different from those of rocks under loading [3]. Therefore, it is important to study the mechanical and energy properties of rocks under the unloading condition. The rock mass in actual excavation projects is mostly anisotropic and presents three-dimensional unequal characteristics [4]. Scientists and engineers assumed that the intermediate principal stress has an important effect on the mechanics and failure characteristics of rock mass under true triaxial loading [5-7]. Therefore, it is important to investigate the lateral unloading mechanics and energy characteristics of rocks subjected to different intermediate principal stresses, which is helpful to understand the unloading failure mechanism of rock masses under real geostress states.

In recent years, a substantial number of laboratory tests were conducted to reveal the macromechanical and failure behaviors of rock masses under different loads, e g., uniaxial compression, conventional triaxial compression [8], and true triaxial compression $[9,10]$. Mogi [11] first employed precise testing methods to study the influence of the combined stress system, particularly of the intermediate principal stress, on rock failure. Ma et al. [12] studied the 
unloading failure and deformation feature of siltstone under different intermediate principal stress coefficients $b$ and discussed the strength feature of the rock mass based on the Mogi-Coulomb strength criterion. At the same time, many scholars have investigated rock failure from the perspective of energy [13]. Xie et al. [14-16] proposed the overall rock failure criterion based on energy dissipation according to the characteristics of energy dissipation and release in the process of rock deformation and failure. Actually, rock masses are discontinuous media containing initial defects, such as grain boundaries, microcracks, and pores; initiation and propagation of microcracks significantly affect the failure of rock materials [17]. In order to investigate the influence of initiation and propagation of microcracks on the failure of rock materials, micromechanical methods [18-20] were employed to understand the failure of rock materials and establish the corresponding strength criteria and constitutive relations. Zhou et al. [21] proposed a nonlinear three-dimensional strength criterion for rock-like materials based on the micromechanical methods, in which the effects of the intermediate principal stress on the failure of rock-like materials are taken into account. Zhou et al. [22] used the real-time CT technique to obtain the computerized tomography (CT) images and CT values for the process of unloading, microcracking, and dilation up to the failure of limestone specimens under different unloading levels and established a damage model based on the CT value and a new failure criterion. Besides, due to the dispersion of rock materials and the expensive and time-consuming laboratory equipment, the rapid development of computers has given scholars new methods to study the properties of rock materials [23]. Different numerical simulation methods such as the finite element method (FEM) [24, 25], discrete element method (DEM) [26-29], smoothed-particle hydrodynamics (SPH) [30], and peridynamics (PD) [31, 32] were proposed to investigate the mechanical behaviors and failure characteristics of rock specimens under different compressive loading conditions. Zhang et al. [33] employed a 3D particlebased discrete element methodology to investigate the mechanical and failure characteristics of fissured marble specimens in true triaxial compression with a new loading stress path.

In this paper, the true triaxial loading and unloading test was carried out with sandstone as the object, in which the effects of the intermediate principal stress on unloading failure and energy dissipation of the rock material are considered. It is of great value for theoretical research and engineering practice.

\section{Materials and Methods}

2.1. Materials and Equipment Used in the Tests. The experiment process used the TRW-3000 rock mechanics test system of Central South University, as is shown in Figure 1. To ensure the homogeneity of the specimens, the specimens were taken from the same sandstone rock block with good homogeneity. The specimen size is $100 \mathrm{~mm} \times 100 \mathrm{~mm} \times 100 \mathrm{~mm}$, the unevenness is less than $0.05 \mathrm{~mm}$, and the nonperpendicularity is less than $0.25^{\circ}$.

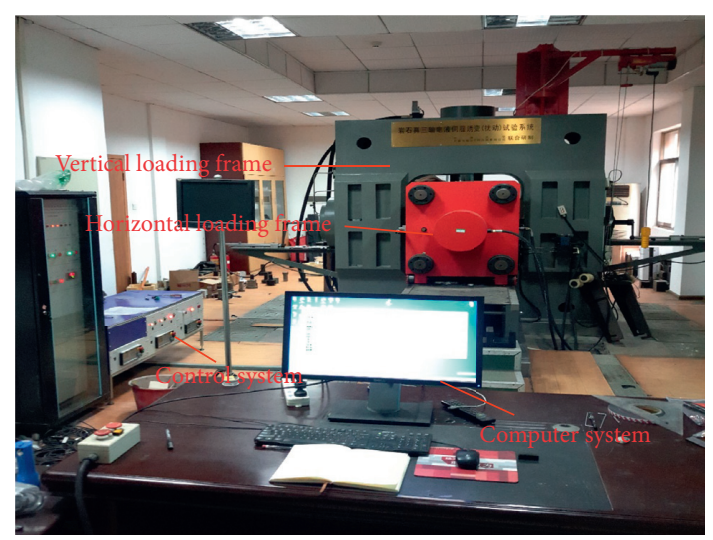

Figure 1: TRW-3000 rock mechanics test system.

2.2. Experimental Scheme and Procedure. To explore the influence of $\sigma_{2}$ on the true triaxial unloading mechanics and energy characteristics of sandstone, a true triaxial loading and unloading test was carried out. The test was divided into two parts as follows:

\section{Part I: true triaxial loading:}

Step 1: all directional stresses were loaded to the initial stress level at a rate of $0.05 \mathrm{MPa}^{-1}$.

Step 2: the stress was kept stable in all directions. After $30 \mathrm{~s}$, when $\sigma_{2}$ and $\sigma_{3}$ remained unchanged, $\sigma_{1}$ was loaded until specimens were destroyed.

Part II: true triaxial lateral unloading:

Step 1: all directional stresses were loaded to the initial stress level at a rate of $0.05 \mathrm{MPa}^{-1}$.

Step 2: the stress was kept stable in all directions. After $30 \mathrm{~s}$, when $\sigma_{2}$ and $\sigma_{3}$ remained unchanged, $\sigma_{1}$ was loaded to a predetermined value $(90 \%$ of the peak strength $\sigma_{1}^{\max }$ obtained by the true triaxial loading test under the same initial stress condition).

Step 3: $\sigma_{1}$ and $\sigma_{2}$ were kept stable, and $\sigma_{3}$ was unloaded until specimens were destroyed. The initial stress level is shown in Table 1. The test stress path diagram is shown in Figure 2.

\section{Results and Discussion of the Mechanical Characteristics}

3.1. Stress-Strain Curve. The rock material is typically inhomogeneous, containing initial defects, such as grain boundaries, microcracks, and pores. Due to the dependence of the load path, the mechanical behaviors of rocks under unloading are different from those under loading. The rock material contains a number of randomly oriented preexisting microcracks. The preexisting microcracks will be closed under loading, but they will be open under unloading, so the deformation of the rock material under unloading is more than under loading. The frictional sliding on preexisting cracks will occur under loading, but the frictionless sliding on preexisting cracks may occur under unloading. The strength of the rock material under unloading is less than under loading. In the micromechanical approach, the 
TABLE 1: Initial stress level.

\begin{tabular}{lccccc}
\hline Type & & Initial stress $(\mathrm{MPa})$ & & Unloading point $(\mathrm{MPa})$ & Unloading rate of $\sigma_{3}\left(\mathrm{MPa} \cdot \mathrm{s}^{-1}\right)$ \\
& $\sigma_{1}^{0}$ & $\sigma_{2}^{0}$ & $\sigma_{3}^{0}$ & - \\
\hline Loading test & 20 & $5,11,17,20$ & 5 & - & 0.05 \\
Lateral unloading test & 20 & $5,11,17,20$ & 5 & $\sigma_{1}=0.9 \sigma_{1}^{\max }$ & - \\
\hline
\end{tabular}

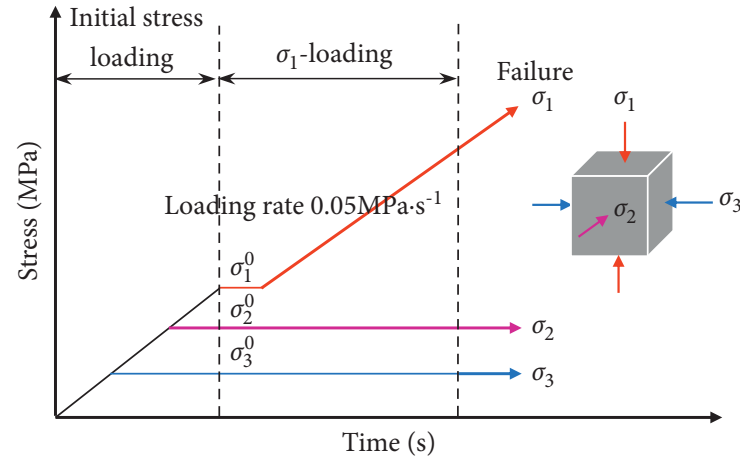

(a)

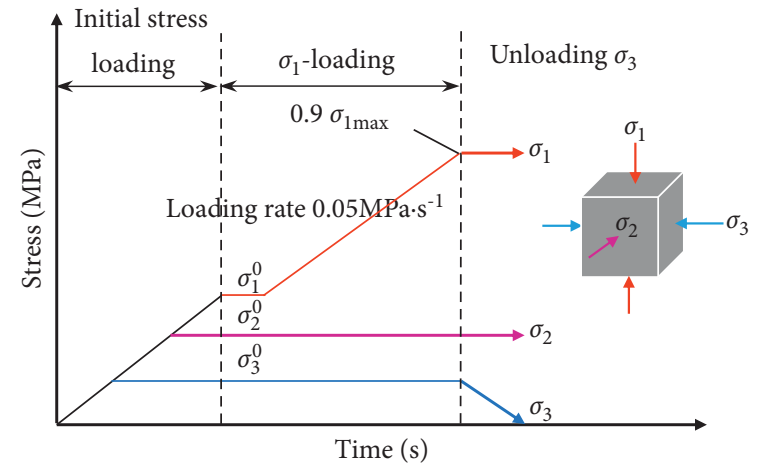

(b)

Figure 2: Stress path schematic diagram of the (a) true triaxial loading test and (b) true triaxial lateral unloading test.

nucleation, growth, and coalescence of microcracks dominate the failure and macroscopic properties of the rock under loading and unloading paths [3].

In this paper, the starting point of the $\sigma_{1}$-loading stage is used as the reference point for data processing. Figure 3 shows the loading and unloading stress-strain curves of sandstone under different $\sigma_{2}$ when $\sigma_{3}^{0}=5 \mathrm{MPa}$ and $\sigma_{1}^{0}=20 \mathrm{MPa}$. According to the loading curves, the deformation trend of the specimens under different $\sigma_{2}$ is the same. The early stage is approximately elastic deformation, and the later stage shows obvious plastic deformation until the final failure. As for the unloading $\sigma_{3}$ curve, the bearing capacity of the specimens is reduced, and obvious lateral expansion occurs when $\sigma_{1}$ is maintained at $0.9 \sigma_{1}^{\max }$. Among them, the direction of $\sigma_{3}$ is the main expansion direction, and the minimum principal strain $\varepsilon_{3}$ increases. As $\sigma_{2}$ increases, the expansion in the unloading direction increases, and the peak strength increases. Sudden brittle failure occurs at the end of unloading $\sigma_{3}$.

3.2. Deformation Modulus and Unloading Ratio. To study the change law of sandstone mechanical parameters under the true triaxial unloading $\sigma_{3}$ condition, the concept of $H$ is introduced to analyze the relationship between mechanical parameters and unloading degree. Considering the initial stress $\sigma_{3}^{0}$ of the specimen and the unloading amount, $H$ is defined as [9]

$$
H=\frac{\sigma_{3}^{0}-\sigma_{3}^{i}}{\sigma_{3}^{0}},
$$

where $\sigma_{3}^{i}$ is the real-time stress value in the $\sigma_{3}$ direction during unloading $\sigma_{3}$ and $H$ reflects the overall unloading degree of $\sigma_{3}$. The initial confining pressure and the magnitude of the unloaded stress in the unloading direction have an obvious impact on the rock deformation, failure, and strength parameters' degradation during the unloading process [34]. Quantitative research on the change law of mechanical parameters during rock unloading by $H$ has strong theoretical and practical significance [35].

Define the true triaxial unloading deformation modulus as

$$
E_{0}=\frac{\sigma_{1}-\sigma_{1}^{0}}{\varepsilon_{1}-\varepsilon_{1}^{0}} .
$$

Figure 4 depicts the $E_{0}-H$ curves of sandstone under different $\sigma_{2}$ during true triaxial unloading. The curves are fitted with the cubic polynomial, and the fitting coefficients $R^{2}$ are all up to 0.99 , a good fitting effect. The curves show that $E_{0}$ gradually decreases with the increase of $H$ during unloading $\sigma_{3}$. At the initial stage of unloading, the curves are relatively gentle, as $H$ increases, the curves gradually become steeper, and the rate of decrease of $E_{0}$ increases. The reason is that the decline of $\sigma_{3}$ is small, and the development of the specimen deformation is slow in the initial stage of unloading, but as $H$ increases, the decline of $\sigma_{3}$ increases, the restraint of the specimen becomes weaker, the bearing capacity of the specimen decreases, and the deformation accelerates. At the same time, the curves under different $\sigma_{2}$ also show certain differences: the curves are generally gentle when $\sigma_{2}$ is small, but the curves become steeper as $\sigma_{2}$ increases, and when the initial stress level is high, a small unloading ratio can cause a significant deformation of the specimen, indicating that when the initial stress level is higher, more energy is stored in the specimen. Under the unloading condition, the energy stored in the specimen is released suddenly, and the failure deformation of the specimen is more significant. 


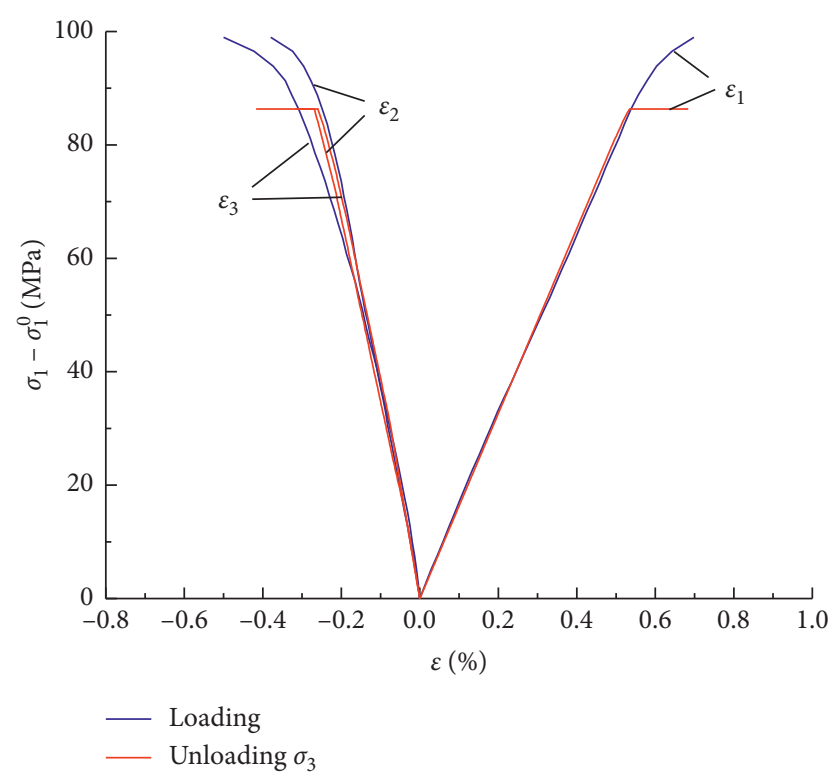

(a)

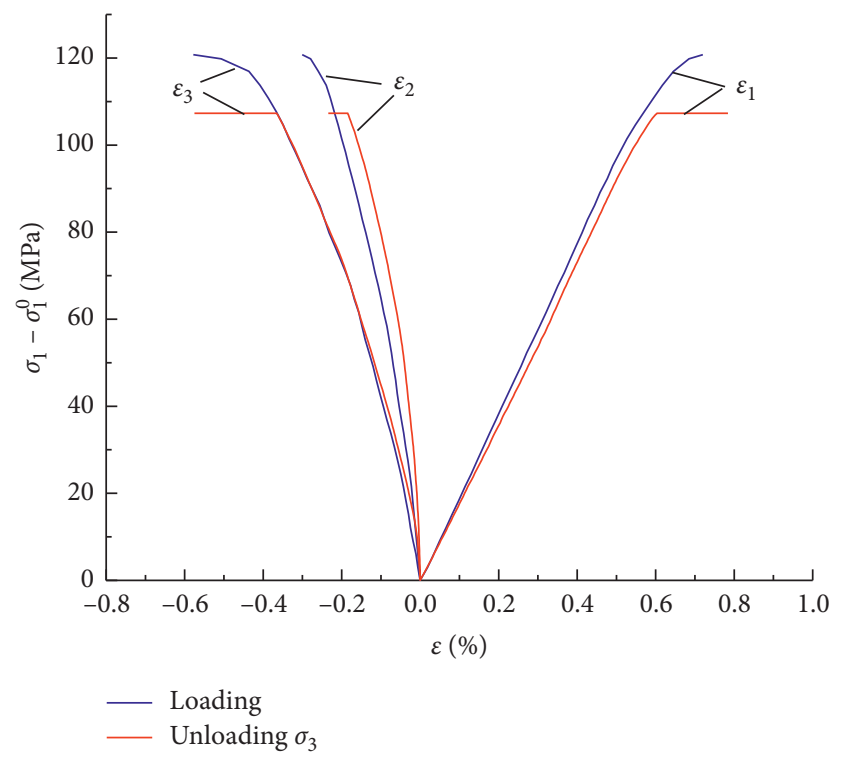

(c)

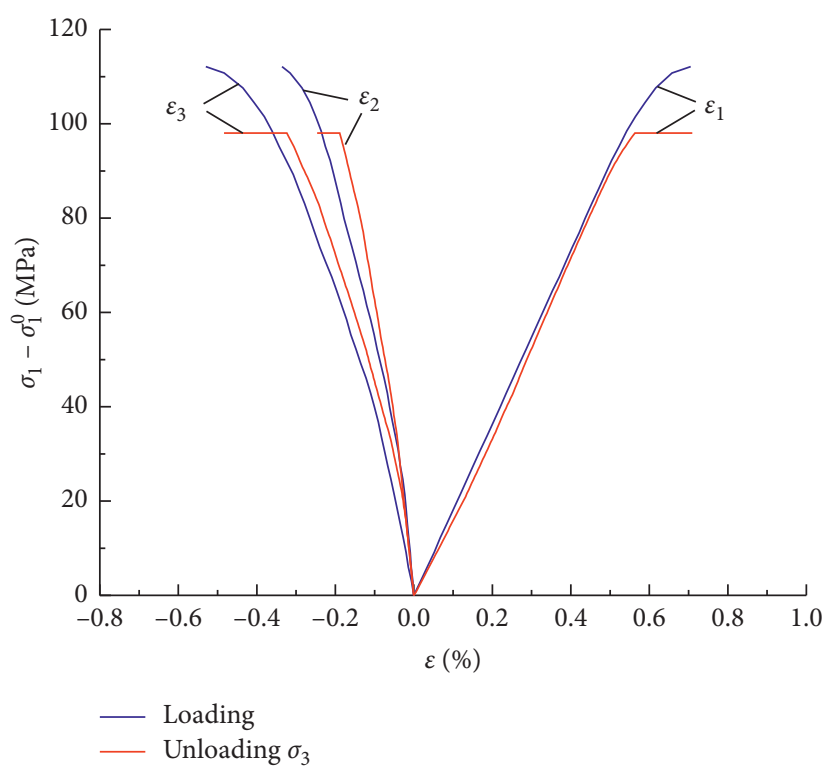

(b)

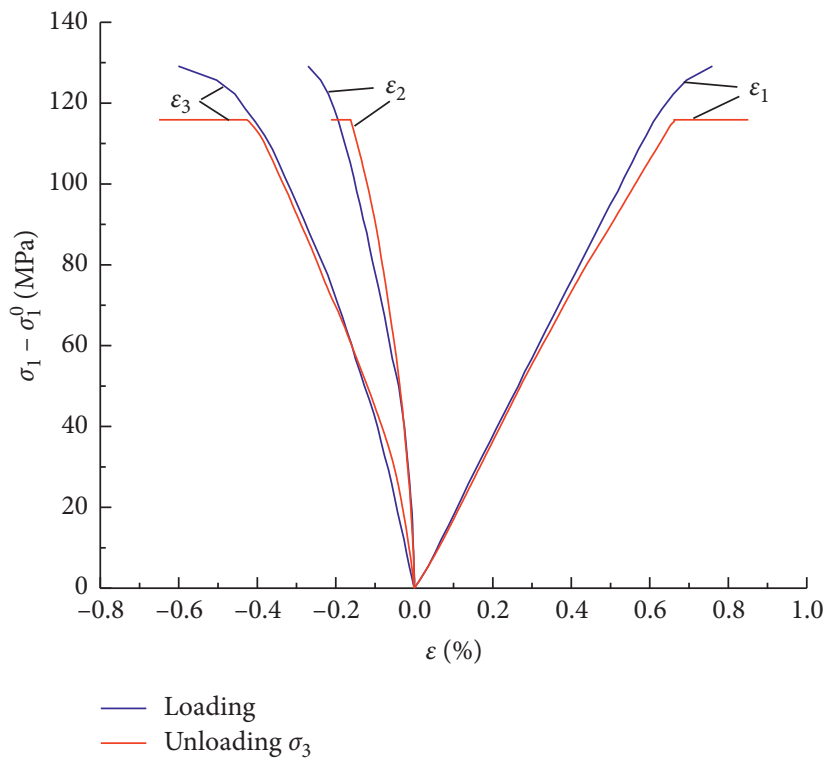

(d)

Figure 3: Loading and unloading stress-strain curves under different $\sigma_{2}$. (a) $\sigma_{2}=5 \mathrm{MPa}$. (b) $\sigma_{2}=11 \mathrm{MPa}$. (c) $\sigma_{2}=17 \mathrm{MPa}$. (d) $\sigma_{2}=20 \mathrm{MPa}$.

3.3. Strength Characteristics. The Mohr-Coulomb criterion is the most commonly used shear failure criterion in practice, but it only considers the influence of $\sigma_{1}$ and $\sigma_{3}$ on rock failure and underestimates rock strength by ignoring the effect of $\sigma_{2}$. To solve this defect, scholars have proposed many rock strength criteria based on the three-dimensional force [36-38].

Among them, through the analysis of numerous true triaxial test data, Mogi found that the yield or failure of the rock is affected by $\sigma_{2}$ and proposed the Mogi yield criterion based on the octahedral shear stress $\tau_{\text {oct }}$ and the effective intermediate principal stress $\sigma_{m, 2}$ [36], which essence is still the shear failure criterion:

$$
\begin{aligned}
\tau_{\mathrm{oct}} & =f\left(\sigma_{m, 2}\right), \\
\tau_{\mathrm{oct}} & =\frac{1}{3} \sqrt{\left(\sigma_{1}-\sigma_{2}\right)^{2}+\left(\sigma_{2}-\sigma_{3}\right)^{2}+\left(\sigma_{1}-\sigma_{3}\right)^{2}}, \\
\sigma_{m, 2} & =\frac{\sigma_{1}+\sigma_{3}}{2} .
\end{aligned}
$$

As the distortional strain energy is proportional to the octahedral shear stress, this criterion is equivalent to asserting that failure will occur when the distortional strain energy reaches some critical value that increases monotonically with $\sigma_{2}$ [39]. The function in the Mogi yield 


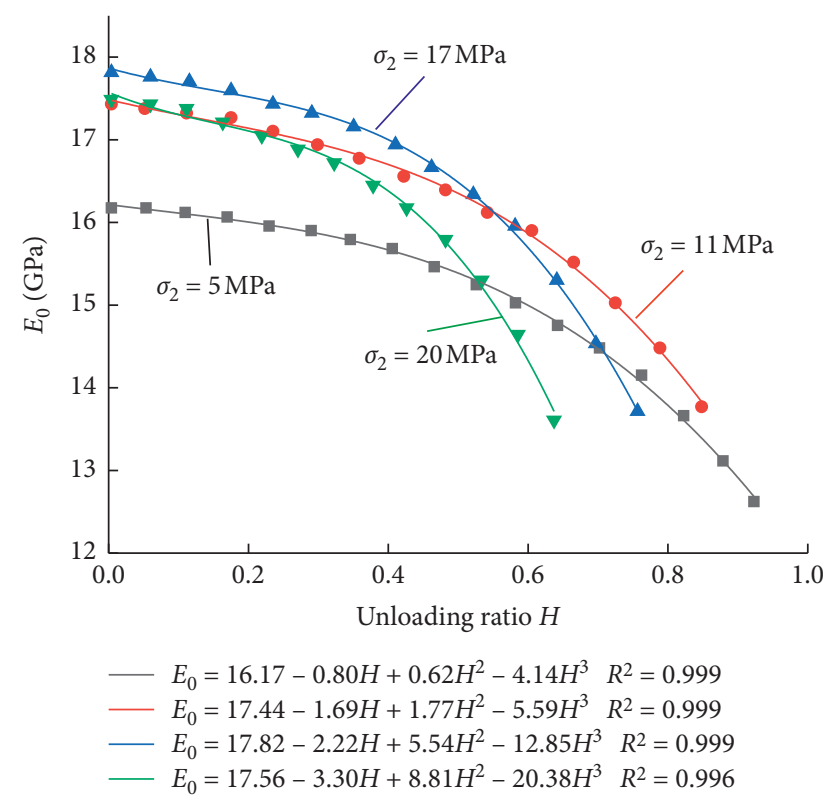

FIgURE 4: The deformation modulus and unloading ratio curves of the sandstone under different $\sigma_{2}$ during true triaxial unloading.

criterion is often regarded as a nonlinear power function. The parameters obtained based on formula (3) cannot well connect with the strength parameters $c$ and $\varphi$ of the Mohr-Coulomb criterion. To solve this problem, Al-Ajmi and Zimmerman $[39,40]$ put forward the view that the $f$ function is linear and used numerous test data to verify it. They found that the linear fitting effect of $\tau_{\text {oct }}$ and $\sigma_{m, 2}$ was good, and then they combined it with the Mohr-Coulomb criterion and renamed it the Mogi-Coulomb criterion:

$$
\tau_{\mathrm{oct}}=a+b \sigma_{m, 2}
$$

where $a$ and $b$ are fitting parameters, and the intensity parameter expression based on the Mohr-Coulomb criterion is

$$
\begin{aligned}
& a=\frac{2 \sqrt{2}}{3} c \cdot \cos \varphi, \\
& b=\frac{2 \sqrt{2}}{3} \sin \varphi .
\end{aligned}
$$

Figure 5 is the fitting curve of sandstone strength based on the Mogi-Coulomb criterion under true triaxial loading and lateral unloading conditions, which is in good agreement with the experimental data, and the fitting coefficients $R^{2}$ are all higher than 0.99 , a good fitting effect, indicating that the criterion can well describe the strength relationship of sandstone. The strength parameters $a$ and $b$ can be approximated from a set of triaxial loading and unloading tests, and then the strength parameters $c$ and $\varphi$ of sandstone can be calculated based on this strength criterion. As is shown in Table 2, compared with the values under the loading path, the $c$ and $\varphi$ values of sandstone under the unloading $\sigma_{3}$ path are all reduced. The cohesive force $c$ decreases by $24.36 \%$, and the internal friction angle $\varphi$ decreases by $16.13 \%$, that is,

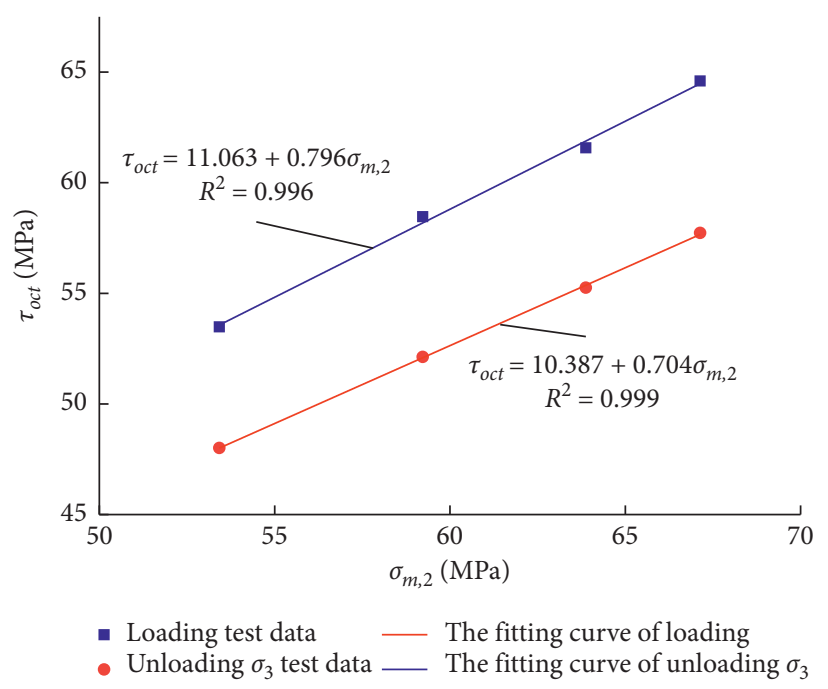

FIgURE 5: Specimen strength fitting curves based on the Mogi-Coulomb criterion.

TABLe 2: Fitting parameters of sandstone under different stress paths.

\begin{tabular}{lccccc}
\hline \multirow{2}{*}{ Loading method } & \multicolumn{5}{c}{ Mogi-Coulomb criterion } \\
& $a$ & $b$ & $c(\mathrm{MPa})$ & $\varphi\left({ }^{\circ}\right)$ & $R^{2}$ \\
\hline $\begin{array}{l}\text { True triaxial loading } \\
\text { True triaxial lateral }\end{array}$ & 11.063 & 0.796 & 21.90 & 57.60 & 0.996 \\
unloading & 10.387 & 0.704 & 16.56 & 48.31 & 0.999 \\
\hline
\end{tabular}

the specimen is softened during unloading $\sigma_{3}$, and the strength is lower than that under the loading path.

\section{Results and Discussion of the Energy Characteristics}

4.1. Energy Calculation Principle. The rock produces deformation during loading, and the heat exchange between the rock and outside during this process is ignored; that is to say, the specimen can be considered as a closed system. According to the first law of thermodynamics,

$$
U=U^{d}+U^{e},
$$

where $U$ is the total work done by the external force during the test, that is, the total energy input; $U^{d}$ is the dissipated energy, which is used to form internal damage and plastic deformation of the specimen, and its change satisfies the second law of thermodynamics, that is, the internal state change conforms to the increasing trend of entropy; and $U^{e}$ is the releasable elastic energy, which is used to generate elastic deformation of the specimen.

This paper takes the starting point of the $\sigma_{1}$-loading stage as the base point of data processing and regards the energy input and dissipation in the initial stress loading stage as changes in the internal energy of the specimen, so it is ignored. The energy of each part of the specimen under the complex stress states can be expressed as equation (7) [14-16]. 


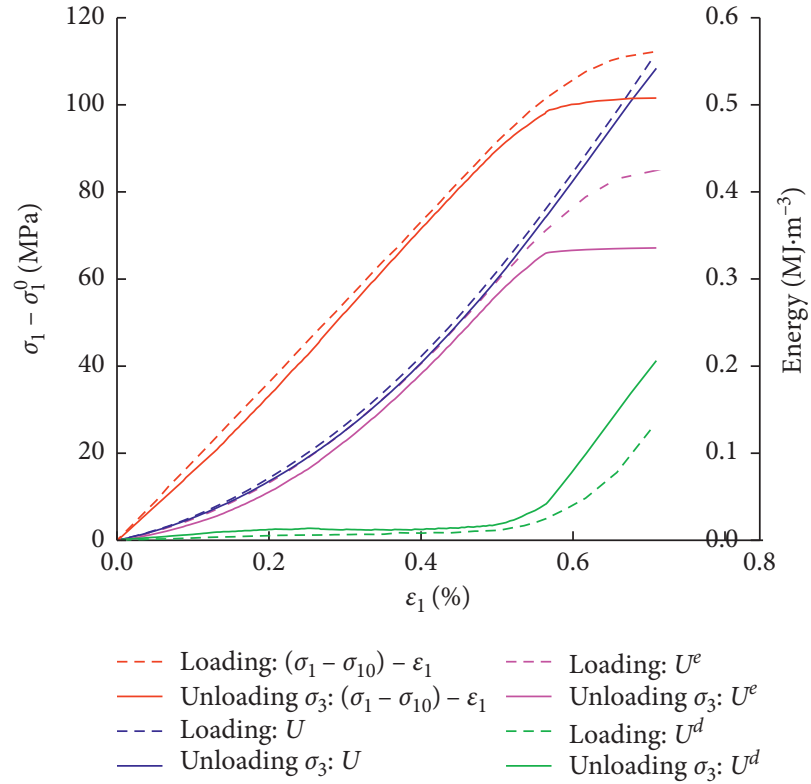

(a)

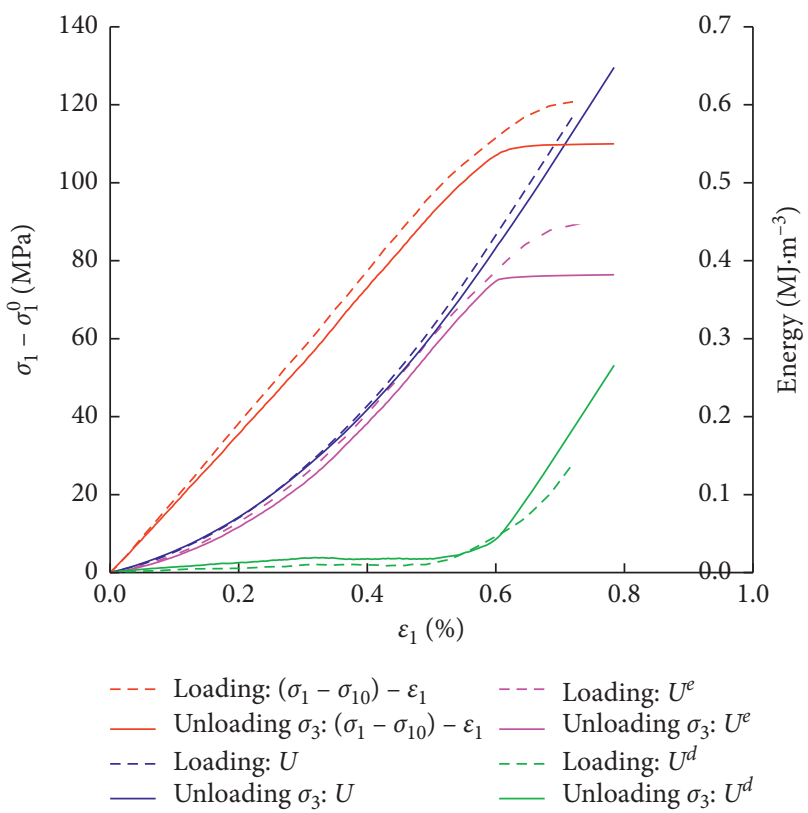

(b)

Figure 6: Energy-strain curves. (a) $\sigma_{3}=5 \mathrm{MPa}$ and $\sigma_{2}=11 \mathrm{MPa}$. (b) $\sigma_{3}=5 \mathrm{MPa}$ and $\sigma_{2}=17 \mathrm{MPa}$.

In equation (7), $\sigma_{1}, \sigma_{2}$, and $\sigma_{3}$ are the maximum, middle, and minimum principal stresses, respectively, $\varepsilon_{1}, \varepsilon_{2}$, and $\varepsilon_{3}$ are the strains in the directions of the principal stresses, $\mu$ is Poisson's ratio, $E$ is the unloading elastic modulus, which is replaced by the elastic modulus in the calculation, and $U_{0}$ and $U_{0}^{e}$ are the total energy input and the releasable elastic energy in the initial stress loading stage.

$$
\begin{aligned}
U & =\int_{0}^{\varepsilon_{1}} \sigma_{1} d \varepsilon_{1}+\int_{0}^{\varepsilon_{2}} \sigma_{2} d \varepsilon_{2}+\int_{0}^{\varepsilon_{3}} \sigma_{3} d \varepsilon_{3}-U_{0}, \\
U^{e} & =\frac{1}{2 E}\left[\sigma_{1}^{2}+\sigma_{2}^{2}+\sigma_{3}^{2}-2 \mu\left(\sigma_{1} \sigma_{2}+\sigma_{2} \sigma_{3}+\sigma_{3} \sigma_{1}\right)\right]-U_{0}^{e} .
\end{aligned}
$$

4.2. Energy-Strain Curve. Figure 6 depicts the energy-strain curve of the specimen under loading and unloading $\sigma_{3}$ conditions, which shows that the initial forces of the two stress paths are the same, so the early changes of the energystrain curve under the two paths are similar. That is to say, the energy is mainly stored as $U^{e}$, and the part converted into $U^{d}$ is very small. However, because the forces of the two stress paths change in the later stage, there are obvious differences in the later stage of the energy-strain curves: according to the loading curve, one part of the energy is stored as $U^{e}$, and the other part of the energy is converted into $U^{d}$. As for the unloading curve, $U^{d}$ increases significantly, while $U^{e}$ remains stable with minor changes, indicating that the energy input in the later stage is used for internal damage and plastic deformation of the specimen, and the excess $U^{d}$ is transformed into the kinetic energy of the falling rock.
4.3. Energy Analysis of Lateral Unloading. Table 3 depicts the energy value of each characteristic point of the specimen under the unloading $\sigma_{3}$ condition. As is shown in Table 3, when $\sigma_{2}$ increases from $5 \mathrm{MPa}$ to $20 \mathrm{MPa}$, all types of energy at the specimen failure point increase, among which the maximum increment is $U^{d}$ : from $0.18 \mathrm{MJ} \cdot \mathrm{m}^{-3}$ to $0.32 \mathrm{MJ} \cdot \mathrm{m}^{-3}$, an increase of $77.8 \%$. Meanwhile, the increment of $U$ and $U^{d}$ increases with the increase of $\sigma_{2}$, but the increment of $U^{e}$ remains unchanged. Figure 7 shows the fitted curves of energy- $\sigma_{2}$ at the unloading failure point under the unloading $\sigma_{3}$ condition when $\sigma_{3}^{0}=5 \mathrm{MPa}$ and $\sigma_{1}^{0}=20 \mathrm{MPa}$, which depict that $U, U^{d}$, and $U^{e}$ are linearly related to $\sigma_{2}$, and the linear fitting coefficients $R^{2}$ are all above 0.9 , a good fitting effect.

Figure 8 depicts the $U^{d}$ - $H$ curve under the unloading $\sigma_{3}$ condition, which shows that $U^{d}$ increases slowly with the increase of $H$ in the initial unloading stage, but as $H$ increases, $U^{d}$ increases rapidly until the final specimen failure. The influence of $\sigma_{2}$ on the change of $U^{d}$ during the unloading process is mainly manifested as follows: with the increase of $\sigma_{2}$, the slope of the curve becomes larger, and the growth rate of $U^{d}$ increases; the specimen deformation consumes more energy under the same unloading amount.

The total energy absorbed by the specimen during the loading process is used to store as $U^{e}$ and convert it into $U^{d}$ for the initiation and propagation of cracks inside the specimen. Therefore, even if the energy input during the loading process is the same, different energy distributions will cause the specimen failure mode to change. Figure 9 is the energy distribution diagram of the specimen under the unloading $\sigma_{3}$ condition when $\sigma_{3}^{0}=5 \mathrm{MPa}$ and $\sigma_{1}^{0}=20 \mathrm{MPa}$, which shows that $U^{e} / U$ is generally above 0.5 , while $U^{d} / U$ increases with the increase of $\sigma_{2}$, indicating that most of the 
TABLE 3: The energy of unloading and failure points under different $\sigma_{2}$.

\begin{tabular}{lcccccccccc}
\hline $\begin{array}{l}\text { Initial stress } \\
(\mathrm{MPa})\end{array}$ & $\begin{array}{c}\text { Unloading } \\
\text { point energy } \\
\left(\mathrm{MJ} \cdot \mathrm{m}^{-3}\right)\end{array}$ & $\begin{array}{c}\text { Unloading } \\
\text { failure point } \\
\text { energy } \\
\left(\mathrm{MJ} \cdot \mathrm{m}^{-3}\right)\end{array}$ & $\begin{array}{c}\text { Unloading } \sigma_{3} \\
\text { energy increase } \\
\left(\mathrm{MJ} \cdot \mathrm{m}^{-3}\right)\end{array}$ \\
$\sigma_{1}^{0}, \sigma_{2}^{0}, \sigma_{3}^{0}$ & $U$ & $U^{e}$ & $U^{d}$ & $U$ & $U^{e}$ & $U^{d}$ & $\triangle U$ & $\Delta U^{e}$ & $\Delta U^{d}$ \\
\hline $20,5,5$ & 0.32 & 0.30 & 0.02 & 0.49 & 0.31 & 0.18 & 0.17 & 0.01 & 0.16 \\
$20,11,5$ & 0.37 & 0.33 & 0.04 & 0.55 & 0.34 & 0.21 & 0.18 & 0.01 & 0.17 \\
$20,17,5$ & 0.43 & 0.38 & 0.05 & 0.65 & 0.38 & 0.27 & 0.22 & 0.00 & 0.22 \\
$20,20,5$ & 0.49 & 0.42 & 0.07 & 0.75 & 0.43 & 0.32 & 0.26 & 0.01 & 0.25 \\
\hline
\end{tabular}

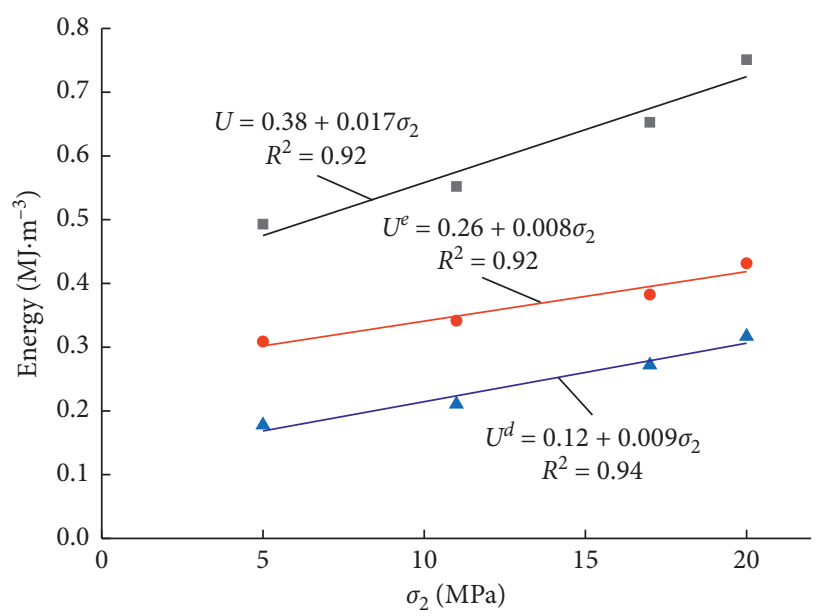

FIgURE 7: The fitting curves of energy- $\sigma_{2}$ at the failure point under the unloading $\sigma_{3}$ condition.

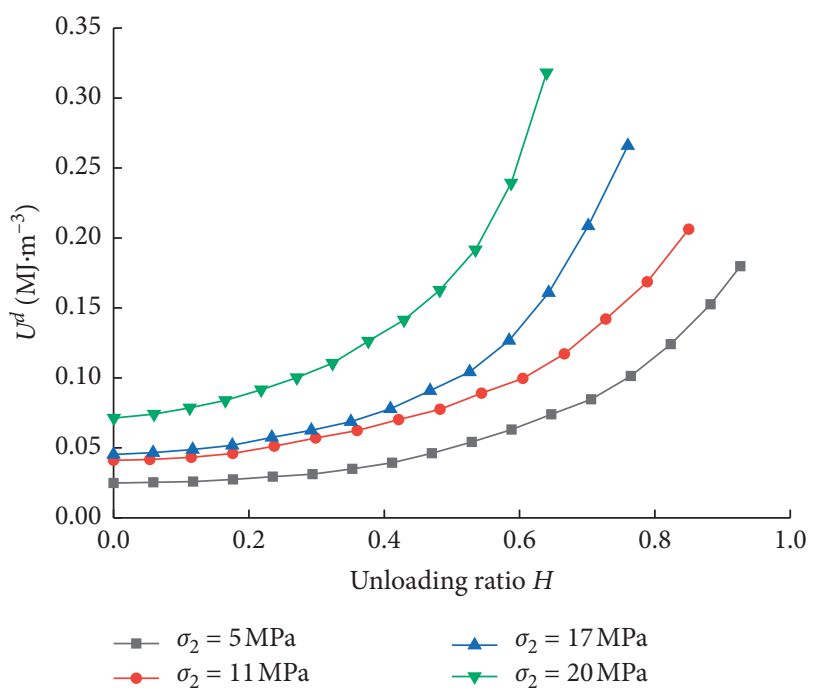

FIGURE 8: Dissipated energy-unloading ratio curves.

total energy absorbed by the specimen under the unloading $\sigma_{3}$ path is converted into $U^{e}$ and stored inside the specimen, but as $\sigma_{2}$ increases, the proportion of $U^{d}$ increases, and specimen destruction consumes relatively more energy.

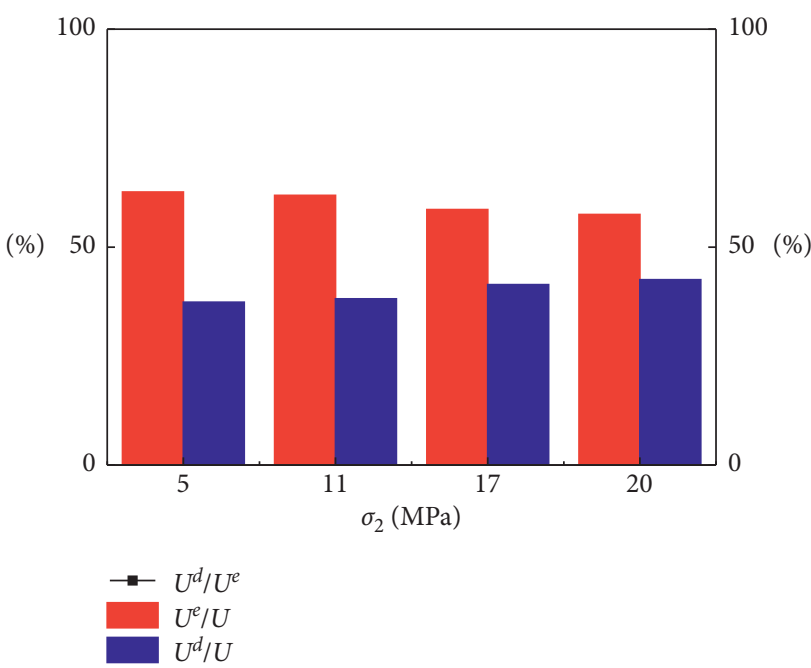

FIGURE 9: Failure point energy distribution under the unloading $\sigma_{3}$ condition.

\section{Conclusion}

(1) Compared with the results of the loading test, the peak strength of the sandstone under the unloading $\sigma_{3}$ path is reduced, and sudden brittle failure occurs at the end of unloading. During the unloading $\sigma_{3}$ process, the unloading direction of the specimen expands significantly, $E$ gradually decreases with the increase of $H$, and the relationship between $E$ and $H$ can be fitted with a cubic polynomial, a good fitting effect.

(2) It is accurate to describe the true triaxial strength characteristics of specimens under different stress paths by using Mogi-Coulomb criterion. Compared with the values under the loading path, the $c$ and $\varphi$ values of the sandstone under the unloading $\sigma_{3}$ path are reduced, of which the cohesive force $c$ decreases by $24.36 \%$, and the internal friction angle $\varphi$ decreases by $16.13 \%$.

(3) $U, U^{d}$, and $U^{e}$ are all positively linearly correlated with $\sigma_{2}$ when the specimen is damaged under the unloading $\sigma_{3}$ condition. $U^{d}$ increases nonlinearly with $H$, and with the increase of $\sigma_{2}$, the slope of the $U^{d}-H$ curve becomes larger, and the specimen consumes more energy under the same unloading amount. Most of the total energy absorbed by the specimen under the unloading $\sigma_{3}$ path is converted into $U^{e}$ and stored inside the specimen, but as $\sigma_{2}$ increases, the $U^{d} / U$ curve rises, the proportion of $U^{d}$ increases, and the energy consumed when the specimen is broken is greater.

\section{Abbreviations}

$\sigma_{1}:$ Maximum principal stress

$C:$ Cohesive force

$\sigma_{2}:$ Intermediate principal stress

$\Phi:$ Internal friction angle 
$\sigma_{3}:$ Minimum principal stress

$U:$ Total energy

$H$ : Unloading ratio

$U^{e}$ : Elastic energy

E: Deformation modulus

$U^{d}$ : Dissipation energy.

\section{Data Availability}

The data used to support the findings of this study are included within the article.

\section{Conflicts of Interest}

The authors declare that there are no conflicts of interest regarding the publication of this paper.

\section{Acknowledgments}

This paper obtained funding from projects (no. 51979293) supported by the National Natural Science Foundation of China. The authors wish to acknowledge the support.

\section{References}

[1] J. Yu, G. Liu, Y. Cai et al., "Time-dependent deformation mechanism for swelling soft-rock tunnels in coal mines and its mathematical deduction," International Journal of Geomechanics, vol. 20, no. 3, pp. 04019186.1-04019186.10, 2020.

[2] A.-Z. Hua and M.-Q. You, "Rock failure due to energy release during unloading and application to underground rock burst control," Tunnelling and Underground Space Technology, vol. 16, no. 3, pp. 241-246, 2001.

[3] X. P. Zhou, "Localization of deformation and stress-strain relation for mesoscopic heterogeneous brittle rock materials under unloading," Theoretical and Applied Fracture Mechanics, vol. 44, no. 1, pp. 27-43, 2005.

[4] R. Cao, R. Yao, J. Meng, Q. Lin, H. Lin, and S. Li, "Failure mechanism of non-persistent jointed rock-like specimens under uniaxial loading: laboratory testing," International Journal of Rock Mechanics and Mining Sciences, vol. 132, p. 104341, 2020.

[5] X.-T. Feng, Y. Gao, X. Zhang, Z. Wang, Y. Zhang, and Q. Han, "Evolution of the mechanical and strength parameters of hard rocks in the true triaxial cyclic loading and unloading tests," International Journal of Rock Mechanics and Mining Sciences, vol. 131, p. 104349, 2020.

[6] R. P. Tiwari and K. S. Rao, "Post failure behavior of a rock mass under the influence of triaxial and true triaxial confinement," Engineering Geology, vol. 84, no. 3-4, pp. 112-129, 2006.

[7] B. Haimson and J. W. Rudnicki, "The effect of the intermediate principal stress on fault formation and fault angle in siltstone," Journal of Structural Geology, vol. 32, no. 11, pp. 1701-1711, 2010.

[8] Y. Wang, D. Liu, J. Han, C. Li, and H. Liu, "Effect of fatigue loading-confining stress unloading rate on marble mechanical behaviors: an insight into fracture evolution analyses," Journal of Rock Mechanics and Geotechnical Engineering, vol. 12, no. 6, pp. 1249-1262, 2020.
[9] X. Si and F. Gong, "Strength-weakening effect and sheartension failure mode transformation mechanism of rockburst for fine-grained granite under triaxial unloading compression," International Journal of Rock Mechanics and Mining Sciences, vol. 131, p. 104347, 2020.

[10] X. Li, F. Feng, D. Li, K. Du, P. G. Ranjith, and J. Rostami, "Failure characteristics of granite influenced by sample height-to-width ratios and intermediate principal stress under true-triaxial unloading conditions," Rock Mechanics and Rock Engineering, vol. 51, no. 5, pp. 1321-1345, 2018.

[11] K. Mogi, "Effect of the intermediate principal stress on rock failure," Journal of Geophysical Research, vol. 72, no. 20, pp. 5117-5131, 1967.

[12] Y. P. Ma, J. T. Li, and S. F. Liu, "Experimental study on lateral unloading mechanical properties of siltstone considering intermediate principal stress," Journal of Central South University (Science and Technology), vol. 50, no. 11, pp. 2792-2800, 2019.

[13] R. Cao, C. Ping, H. Lin, and X. Fan, "Experimental and numerical study of the failure process and energy mechanisms of rock-like materials containing cross un-persistent joints under uniaxial compression," PLos One, vol. 12, no. 12, p. e0188646, 2017.

[14] H. P. Xie, R. D. Peng, J. U. Yang, and H. Zhou, "Energy analysis of rock failure," Chinese Journal of Rock Mechanics and Engineering, vol. 24, no. 15, pp. 2603-2608, 2005.

[15] H. P. Xie, Y. Ju, L. Y. Li, and R. D. Peng, "Energy mechanism of deformation and failure of rock masses," Chinese Journal of Rock Mechanics and Engineering, vol. 27, no. 9, pp. 1729-1740, 2008.

[16] H. P. Xie, J. U. Yang, and L. Y. Li, "Criteria for strength and structural failure of rocks based on energy dissipation and energy release principle," Chinese Journal of Rock Mechanics and Engineering, vol. 24, no. 17, pp. 3003-3010, 2005.

[17] X. P. Zhou and H. Q. Yang, "Dynamic damage localization in crack-weakened rock mass: strain energy density factor approach," Theoretical \& Applied Fracture Mechanics, vol. 97, pp. 289-302, 2018.

[18] X. P. Zhou, "Triaxial compressive behavior of rock with mesoscopic heterogenous behavior: strain energy density factor approach," Theoretical and Applied Fracture Mechanics, vol. 45, no. 1, pp. 46-63, 2006.

[19] X.-P. Zhou, Y.-X. Zhang, Q.-L. Ha, and K.-S. Zhu, "Micromechanical modelling of the complete stress-strain relationship for crack weakened rock subjected to compressive loading," Rock Mechanics and Rock Engineering, vol. 41, no. 5, pp. 747-769, 2008.

[20] X. P. Zhou and H. Q. Yang, "Micromechanical modeling of dynamic compressive responses of mesoscopic heterogenous brittle rock," Theoretical and Applied Fracture Mechanics, vol. 48, no. 1, pp. 1-20, 2007.

[21] X.-P. Zhou, Y.-D. Shou, Q.-H. Qian, and M.-H. Yu, “Threedimensional nonlinear strength criterion for rock-like materials based on the micromechanical method," International Journal of Rock Mechanics and Mining Sciences, vol. 72, pp. 54-60, 2014.

[22] X. P. Zhou, Y. X. Zhang, and Q. L. Ha, "Real-time computerized tomography (CT) experiments on limestone damage evolution during unloading," Theoretical and Applied Fracture Mechanics, vol. 50, no. 1, pp. 49-56, 2008.

[23] M. Kou, X. Liu, S. Tang, and Y. Wang, “3-D X-ray computed tomography on failure characteristics of rock-like materials under coupled hydro-mechanical loading," Theoretical and Applied Fracture Mechanics, vol. 104, p. 102396, 2019. 
[24] C. A. Tang, "Numerical simulation of progressive rock failure and associated seismicity," International Journal of Rock Mechanics and Mining Sciences, vol. 34, no. 2, pp. 249-261, 1997.

[25] C. A. Tang and S. Q. Kou, "Crack propagation and coalescence in brittle materials under compression," Engineering Fracture Mechanics, vol. 61, no. 3-4, pp. 311-324, 1998.

[26] J. Yu, W. Yao, K. Duan, X. Liu, and Y. Zhu, "Experimental study and discrete element method modeling of compression and permeability behaviors of weakly anisotropic sandstones," International Journal of Rock Mechanics and Mining Sciences, vol. 134, p. 104437, 2020.

[27] P. A. Cundall and O. Strack, "A discrete numerical model for granular assemblies,” Géotechnique, vol. 30, no. 3, pp. 331336, 2008.

[28] D. O. Potyondy and P. A. Cundall, "A bonded-particle model for rock," International Journal of Rock Mechanics and Mining Sciences, vol. 41, no. 8, pp. 1329-1364, 2004.

[29] M. M. Kou, Y. J. Lian, and Y. T. Wang, "Numerical investigations on crack propagation and crack branching in brittle solids under dynamic loading using bond-particle model," Engineering Fracture Mechanics, vol. 212, pp. 41-56, 2019.

[30] G. W. Ma, X. J. Wang, and F. Ren, "Numerical simulation of compressive failure of heterogeneous rock-like materials using SPH method," International Journal of Rock Mechanics and Mining Sciences, vol. 48, no. 3, pp. 353-363, 2011.

[31] Y. Wang, X. Zhou, and X. Xu, "Numerical simulation of propagation and coalescence of flaws in rock materials under compressive loads using the extended non-ordinary statebased peridynamics," Engineering Fracture Mechanics, vol. 163, pp. 248-273, 2016.

[32] Y.-T. Wang, X.-P. Zhou, and M.-M. Kou, “Three-dimensional numerical study on the failure characteristics of intermittent fissures under compressive-shear loads," Acta Geotechnica, vol. 14, no. 4, pp. 1161-1193, 2019.

[33] Y. Zhang, S. Liu, M. Kou, and Z. Wang, "Mechanical and failure characteristics of fissured marble specimens under true triaxial compression: insights from 3-D numerical simulations," Computers and Geotechnics, vol. 127, no. 7, p. 103785, 2020.

[34] F. Xiao, D. Jiang, F. Wu et al., "Effects of prior cyclic loading damage on failure characteristics of sandstone under truetriaxial unloading conditions," International Journal of Rock Mechanics and Mining Sciences, vol. 132, p. 104379, 2020.

[35] D. Y. Li, Z. Sun, X. B. Li, and T. Xie, "Mechanical response and failure characteristics of granite under different stress paths in triaxial loading and unloading conditions," Chinese Journal of Rock Mechanics and Engineering, vol. 35, no. 2, pp. 34493457, 2016.

[36] K. Mogi, "Fracture and flow of rocks under high triaxial compression," Journal of Geophysical Research, vol. 76, no. 5, pp. $1255-1269,1971$.

[37] D. C. Drucker and W. Prager, "Soil mechanics and plastic analysis or limit design," Quarterly of Applied Mathematics, vol. 10, no. 2, pp. 157-165, 1952.

[38] L. Zhang and H. Zhu, "Three-dimensional Hoek-Brown strength criterion for rocks," Journal of Geotechnical and Geoenvironmental Engineering, vol. 133, no. 9, pp. 1128-1135, 2007.

[39] A. M. Al-Ajmi and R. W. Zimmerman, "Relation between the Mogi and the coulomb failure criteria," International Journal of Rock Mechanics and Mining Sciences, vol. 42, no. 3, pp. 431-439, 2005.
[40] A. M. Al-Ajmi and R. W. Zimmerman, "Stability analysis of vertical boreholes using the Mogi-Coulomb failure criterion," International Journal of Rock Mechanics and Mining Sciences, vol. 43, no. 8, pp. 1200-1211, 2006. 